\title{
Clinical Reasoning: A 33-Year-Old Patient With Left-Sided Hemiparesis and Anarthria
}

Sean Schowalter, MD, Douglas I. Katz, MD, and David J. Lin, MD

Neurology ${ }^{\circledR}$ 2021;96:128-133. doi:10.1212/WNL.0000000000010809

\section{Section 1}

A 33-year-old man with a history of cardiac thrombus (noncompliant with warfarin) and a prior stroke presented with left-sided weakness and inability to speak. Head CT showed a hyperdense right middle cerebral artery. He received IV tissue plasminogen activator followed by thrombectomy.

On day 2, the patient had worsening left-sided weakness. Repeat CT scan showed hemorrhagic conversion within the right basal ganglia with $6 \mathrm{~mm}$ of midline shift. On examination, he was alert, oriented, and able to follow complex commands. Phonetically, he could only grunt, requiring responses to be obtained through writing and gestures. He had a left facial droop and was unable to open his mouth, puff out his cheeks, protrude his tongue, or manage his saliva. On motor testing, he had a left hemiparesis with hyperreflexia. He had no fasciculations.

The patient ultimately required percutaneous endoscopic gastrostomy placement for dysphagia and was discharged to an inpatient rehabilitation facility.

The patient's prior stroke occurred 4 years earlier. Per chart review, he presented with a right facial droop, dysarthria, and expressive aphasia, and was found to have infarcts in the bilateral frontal lobes. He made a successful recovery with no residual deficits.

\section{Question for Consideration:}

1. Is the patient's speech/language disorder apraxia, aphasia, or anarthria?
Correspondence

Dr. Schowalter

schows@bu.edu

GO TO SECTION 2

From the Beth Israel Deaconess Medical Center (S.S.), Boston; Boston University School of Medicine (D.I.K.); and Massachusetts General Hospital (D.J.L.), Boston.

Go to Neurology.org/N for full disclosures. Funding information and disclosures deemed relevant by the authors, if any, are provided at the end of the article. 


\section{Section 2}

Distinguishing among various speech motor and language disorders is critical for both localization and prognosis after stroke. Aphasia is defined as a disturbance in language and is classically divided into receptive and expressive aphasia. In receptive aphasia, patients have difficulty understanding written and spoken language and thus will be unable to follow commands or respond appropriately. ${ }^{1}$ Typically, these patients are unaware of their deficits, and will speak in long-winded sentences that make little sense. Lesions responsible for receptive aphasia occur in the posterior temporal area of the dominant hemisphere, known as Wernicke area. Patients with expressive aphasia, on the other hand, have no trouble understanding and following spoken or written commands. When speaking or writing, however, these patients often have improper grammar and difficulty with word finding. The difficulty with word finding can manifest as neologisms, word substitutions, and difficulty with pronunciation. Expressive aphasia classically localizes to Broca area or the inferior frontal gyrus.

Orofacial apraxia is an inability to perform skilled movements of face, tongue, and oropharynx despite normal understanding and no motor weakness. ${ }^{2}$ When asked to show how to blow a kiss or lick their lips, patients are unable to perform these tasks. However, automatic movements such as licking their lips when dry are preserved. Speech is also affected in a similar manner, with retained ability to carry on automatic conversations such as greetings, but distortion of lower frequency words as patients struggle to properly coordinate the muscles of speech production. Ability to read and write is maintained. Orofacial apraxia is almost always caused by lesions in the anterior insula and adjacent frontocentral operculum of the left hemisphere.

Anarthria is a complete loss of speech motor ability.

Given that our patient could not eat, chew, swallow, or produce any vocalizations, yet had preserved written language production and language comprehension, we concluded that our patient was anarthric and not aphasic. Further examination showed a positive jaw-jerk reflex, a negative gag reflex, and no fasciculations of the tongue, oropharynx, or laryngeal muscles. Cerebellar testing was without tremor or dysmetria on finger to nose testing, and he had normal rapid alternating movements. Notably, his face moved well when yawning or spontaneously laughing.

\section{Question for Consideration:}

1. Based on the patient's clinical characteristics, where would you localize his lesion?

\section{GO TO SECTION 3}




\section{Section 3}

Anarthria can localize to the bilateral cortex, bilateral basal ganglia, cerebellum, brainstem, or bilateral lower motor neurons. ${ }^{3}$ Given our patients' hyperreflexia, lack of fasciculations, and retained ability to yawn and laugh, we concluded that a lower motor lesion affecting the cranial nerve nuclei or peripheral facial nerves was unlikely. Normal cerebellar examination also made a cerebellar lesion unlikely.

To differentiate between basal ganglia and cortical lesions, MRI was reviewed (figure, B), showing subacute infarcts in the right temporal operculum, subcortical frontal operculum,

Figure Axial MRI of Prior and Recent Stroke

\section{A. Prior stroke}
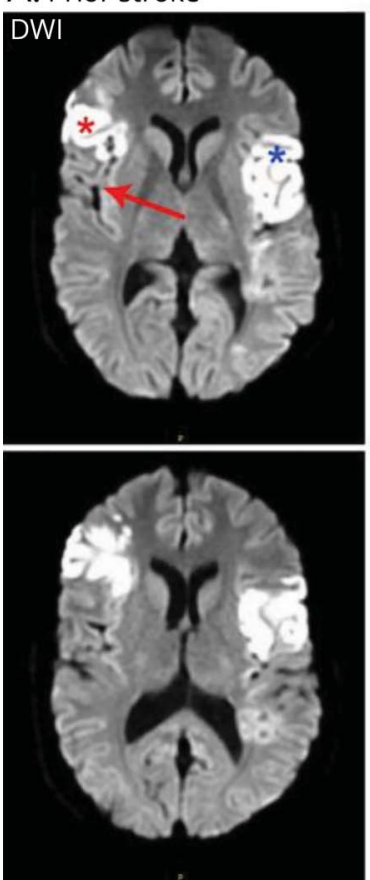

B. Recent stroke
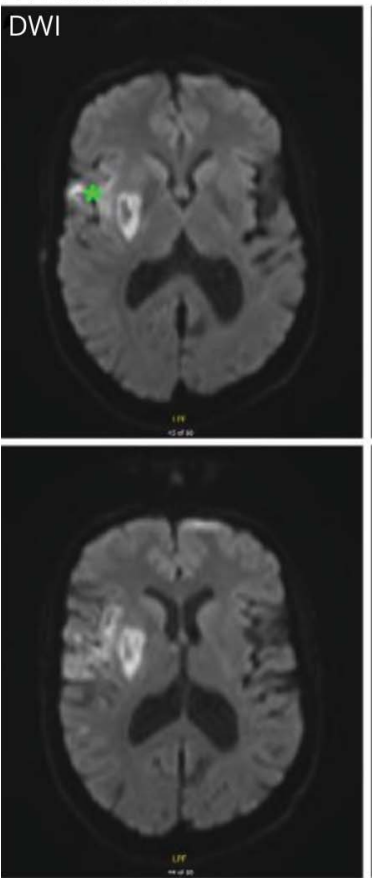
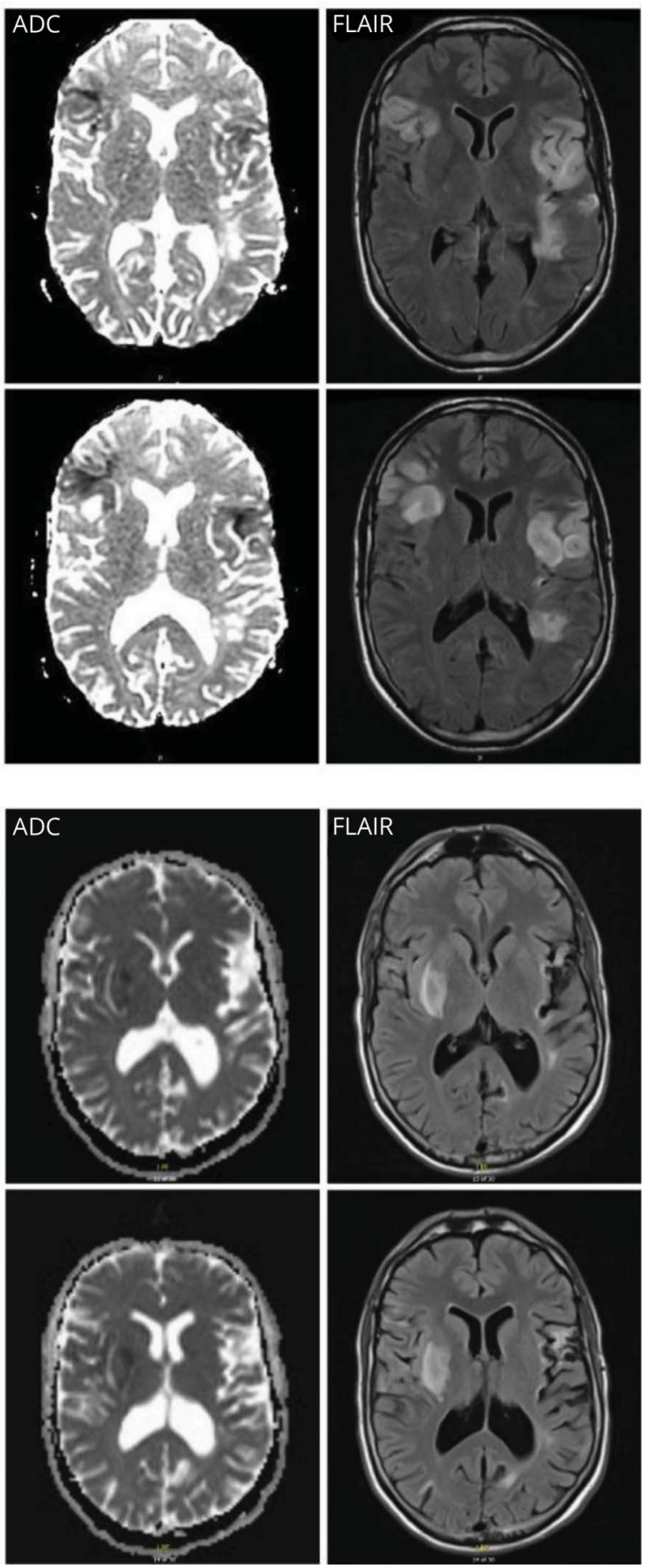
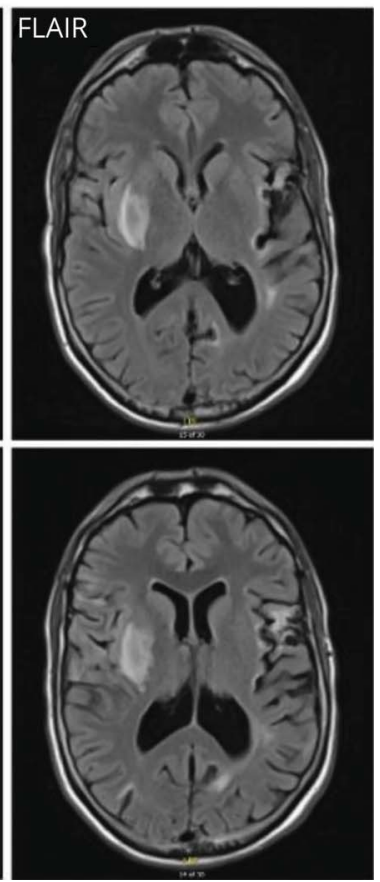

Prior stroke (A) produced bilateral perisylvian, opercular ischemic lesions. The red arrow indicates the right sylvian fissure; red $\star$, stroke in right frontal operculum; blue $\star$, stroke in left frontal/temporal opercular and insular regions. The recent stroke (B) displays an acute ischemic lesion in the right frontotemporal operculum (green $\star$ ) and in the right basal ganglia (putamen). Encephalomalacia from the prior stroke in the left frontotemporal operculum is still visible. $A D C=$ apparent diffusion coefficient; $\mathrm{DWI}$ = diffusion-weighted imaging; FLAIR = fluid-attenuated inversion recovery. 
insula, and putamen. There was encephalomalacia from previous infarcts, involving the left frontal and temporal operculum, confirming bilateral cortical localization of the syndrome.

Imaging from the previous hospitalization was obtained and reviewed (figure, A), demonstrating acute infarcts in the left insula, left temporal operculum, and right frontal operculum.

\section{Questions for Consideration:}

1. Our patient's constellation of symptoms constitutes what syndrome?

2. What is the expected recovery for this patient?

GO TO SECTION 4 


\section{Section 4}

The clinical and neuroimaging findings of orofacial paralysis, anarthria, retained yawning and laughing, as well as bilateral inferior frontal lobe strokes are characteristic of bilateral opercular syndrome, also known as Foix-Chavany-Marie syndrome. ${ }^{4}$

Bilateral opercular syndrome is a rare form of pseudobulbar palsy. It is differentiated from bilateral peripheral cranial nerve or brainstem lesions by the preserved ability to smile, laugh, and yawn. This is because spontaneous facial expressions are produced through contributions of the thalamus, hypothalamus, and extrapyramidal tract. The selective paralysis of voluntary muscle weakness is termed autonomic-voluntary dissociation.

There is little information regarding long-term recovery in these patients. Most case reports have described "poor recovery" with respect to dysarthria, anarthria, and dysphagia after 4 weeks of initial insult and intensive therapy. One case report described slow, incomplete improvements in speech and dysarthria after extended periods of rehabilitation. ${ }^{5}$

We followed the patient over a 6-month period following stroke in order to characterize his course of recovery. Over this time period, he regained the ability to lift his arm in flexor synergy and move his fingers individually. Speech improved from complete anarthria to unintelligible dysarthria at 4 weeks, and finally to moderate dysarthria with only some words requiring repetition at 6 months. Cheek puff improved from complete inability at onset to a weak cheek puff with air escaping on compression. At 6 months, dysphagia improved to the point that he could tolerate a regular diet with thin liquids. Saliva management remained a problem and he frequently had to wipe his mouth with a napkin (video 1).

\section{Discussion}

Despite documentation of "expressive aphasia," our patient likely had bilateral opercular syndrome after his first stroke, in which MRI showed acute strokes with lesions in the bilateral perisylvian, opercular regions. He made a complete recovery within 6 months and had no residual deficits until 4 years later, when he had a new right-sided stroke. The second, purely right-sided stroke led to a recurrent bilateral opercular syndrome by affecting the portion of brain that had undergone neuroplastic reorganization to recover bulbar motor functions after the first stroke.

Bilateral opercular syndrome often involves bilateral lesions to the frontal operculum that includes the inferior portion of the precentral gyrus, the pars triangularis, and the opercularis of the inferior frontal gyrus. The precentral component involves the primary motor cortex, the portion of the motor homunculus controlling the face, lips, tongue, and pharynx. ${ }^{6}$ Thus, bilateral opercular syndrome is largely a disorder of facial muscle paresis and oropharyngeal motor control, not one of language. It is therefore plausible to conclude that a stroke causing bilateral opercular syndrome should follow a recovery pattern similar to other strokes causing central facial paresis.

Two prior studies have characterized orofacial recovery after stroke. One study followed patients for 2 years after stroke (median enrollment 40 days after stroke) and found negligible improvements in maximum lip force, maximum bite force, chewing efficiency, and hand grip strength in patients receiving no rehabilitation therapy. ${ }^{7}$ Another study enrolled patients 2 days to 10 years after stroke with dysphagia. After 5 weeks of oral training, all patients, regardless of time since stroke, improved significantly in both lip force and swallowing capacity. ${ }^{8}$

The improvement in dysphagia seen in this study is consistent with recent studies demonstrating recovery of taskspecific activities of the upper extremities in the setting of proper rehabilitation. ${ }^{9}$ One promising strategy involves a rehabilitation technique called constraint-induced movement therapy, in which patients are forced to perform activities using their affected arm and prevented from using their unaffected limb. Reasons for improvement with intensive therapy are likely multifactorial, including but not limited to preventing learned nonuse, overcoming neuromuscular adaptation, and providing adequate therapy intensity and duration to promote motor learning of complex movements. ${ }^{10}$

The patient presented in this report improved with early, persistent rehabilitation, along with home exercises and practice. The improvement in function over a 6-month period in this individual with serial damage to bilateral motor networks supports the potential of neuroplasticity and active rehabilitation efforts to promote recovery.

\section{Study Funding}

No targeted funding reported.

\section{Disclosure}

The authors report no disclosures relevant to the manuscript. Go to Neurology.org/ $\mathrm{N}$ for full disclosures.

\section{Appendix Authors}

\begin{tabular}{lll}
\hline Name & Location & Contribution \\
\hline $\begin{array}{l}\text { Sean } \\
\text { Schowalter, } \\
\text { MD }\end{array}$ & $\begin{array}{l}\text { Beth Israel Deaconess } \\
\text { Medical Center, Boston }\end{array}$ & $\begin{array}{l}\text { Designed, conceptualized, } \\
\text { and drafted manuscript }\end{array}$ \\
\hline $\begin{array}{l}\text { Douglas I. } \\
\text { Katz, MD }\end{array}$ & $\begin{array}{l}\text { Boston University } \\
\text { School of Medicine }\end{array}$ & $\begin{array}{l}\text { Advised and reviewed } \\
\text { manuscript for intellectual } \\
\text { content }\end{array}$ \\
\hline $\begin{array}{l}\text { David J. Lin, } \\
\text { MD }\end{array}$ & $\begin{array}{l}\text { Massachusetts General } \\
\text { Hospital, Boston }\end{array}$ & $\begin{array}{l}\text { Advised and reviewed } \\
\text { manuscript for intellectual } \\
\text { content }\end{array}$ \\
& & \\
\hline
\end{tabular}




\section{References}

1. Hillis AE. Aphasia: progress in the last quarter of a century. Neurology 2007;69: 200-213.

2. Caplan L, Van Gijn J, eds. Stroke Syndromes, 3rd ed. Cambridge: Cambridge University Press; 2012.

3. Duffy JR. Motor Speech Disorders, 3rd ed. St Louis: Elsevier-Health Sciences Division; 2012.

4. Bakar M, Kirshner HS, Niaz F. The opercular-subopercular syndrome: four cases with review of the literature. Behav Neurol 1998;11:97-103.

5. Cho AR, Lim YH, Chung SH, Choi EH, Lim JY. Bilateral anterior opercular syndrome with partial Kluver-Bucy syndrome in a stroke patient: a case report. Ann Rehabil Med 2016;40:540-544.
6. Mao CC, Coull BM, Golper LA, Rau MT. Anterior operculum syndrome. Neurology 1989;39:1169.

7. Schimmel M, Leemann B, Schnider A, Herrmann FR, Kiliaridis S, Müller F. Changes in oro-facial function and hand-grip strength during a 2-year observation period after stroke. Clin Oral Invest 2013;17:867-876.

8. Hägg M, Anniko M. Lip muscle training in stroke patients with dysphagia. Acta Otolaryngol 2008;128:1027-1033.

9. Page SJ, Sisto S, Levine P, McGrath RE. Efficacy of modified constraint-induced movement therapy in chronic stroke (a single-blinded randomized controlled trial). Arch Phys Med Rehabil 2004;85:14-18.

10. Page SJ, Gater DR, Bach-y-Rita P. Reconsidering the motor recovery plateau in stroke rehabilitation. Arch Phys Med Rehabil 2004;85:1377-1381.

\section{COVID-19 and Neurologic Disease: Call for Papers!}

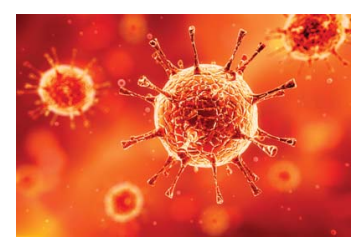

The editors of Neurology are interested in papers that address the neurological aspects of COVID-19 infection and challenges to the management of patients with chronic neurological conditions who have, or are at risk for, the infection. Relevant papers that pass initial internal review will undergo expedited peer review and online publication. We will consider papers posted in preprint servers.

Submit observational studies and clinical trials as Articles and case series and case reports under the Clinical/Scientific Notes category to https://submit.neurology.org/ today!

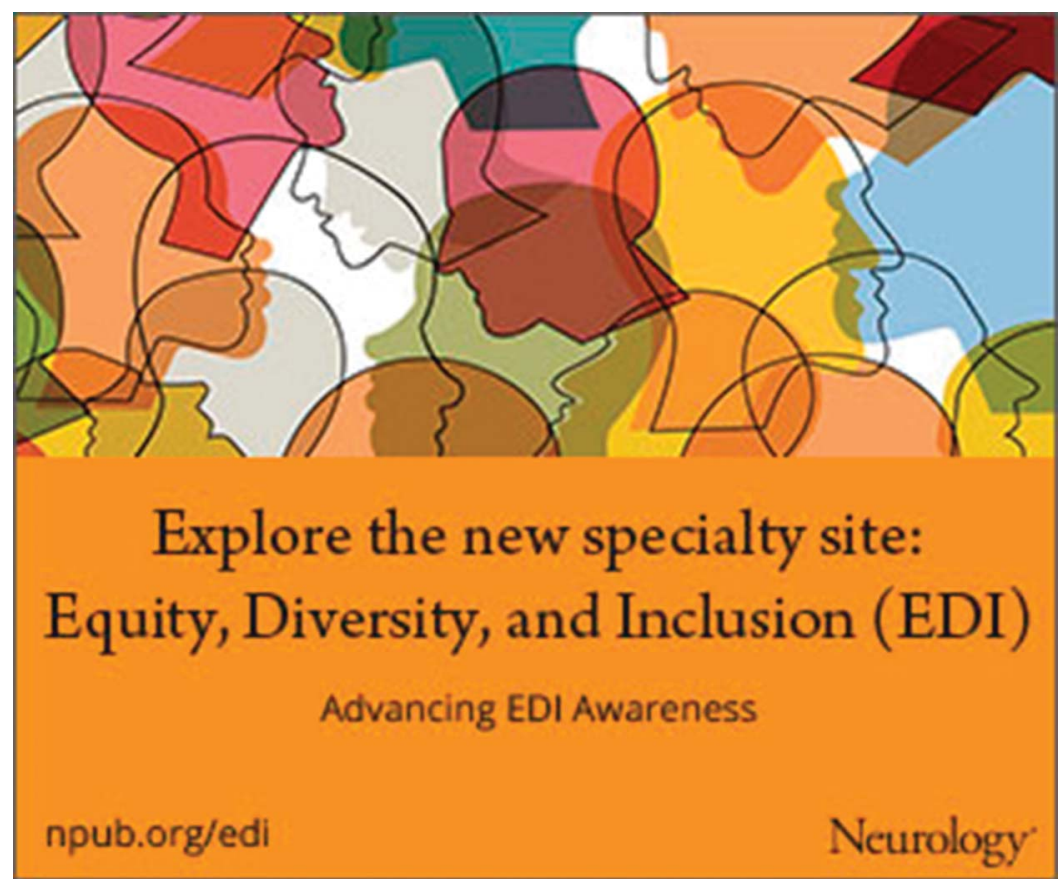




\section{Neurology}

\section{Clinical Reasoning: A 33-Year-Old Patient With Left-Sided Hemiparesis and Anarthria}

Sean Schowalter, Douglas I. Katz and David J. Lin

Neurology 2021;96;128-133 Published Online before print September 10, 2020

DOI 10.1212/WNL.0000000000010809

This information is current as of September 10, 2020

\begin{tabular}{|c|c|}
\hline $\begin{array}{l}\text { Updated Information \& } \\
\text { Services }\end{array}$ & $\begin{array}{l}\text { including high resolution figures, can be found at: } \\
\text { http://n.neurology.org/content/96/3/128.full }\end{array}$ \\
\hline References & $\begin{array}{l}\text { This article cites } 8 \text { articles, } 2 \text { of which you can access for free at: } \\
\text { http://n.neurology.org/content/96/3/128.full\#ref-list-1 }\end{array}$ \\
\hline Subspecialty Collections & $\begin{array}{l}\text { This article, along with others on similar topics, appears in the } \\
\text { following collection(s): } \\
\text { All Rehabilitation } \\
\text { http://n.neurology.org/cgi/collection/all_rehabilitation } \\
\text { Motor Control } \\
\text { http://n.neurology.org/cgi/collection/motor_control } \\
\text { Stroke in young adults } \\
\text { http://n.neurology.org/cgi/collection/stroke_in_young_adults }\end{array}$ \\
\hline Permissions \& Licensing & $\begin{array}{l}\text { Information about reproducing this article in parts (figures,tables) or in } \\
\text { its entirety can be found online at: } \\
\text { http://www.neurology.org/about/about_the_journal\#permissions }\end{array}$ \\
\hline Reprints & $\begin{array}{l}\text { Information about ordering reprints can be found online: } \\
\text { http://n.neurology.org/subscribers/advertise }\end{array}$ \\
\hline
\end{tabular}

Neurology ${ }^{\circledR}$ is the official journal of the American Academy of Neurology. Published continuously since 1951 , it is now a weekly with 48 issues per year. Copyright (C) 2020 American Academy of Neurology. All rights reserved. Print ISSN: 0028-3878. Online ISSN: 1526-632X.

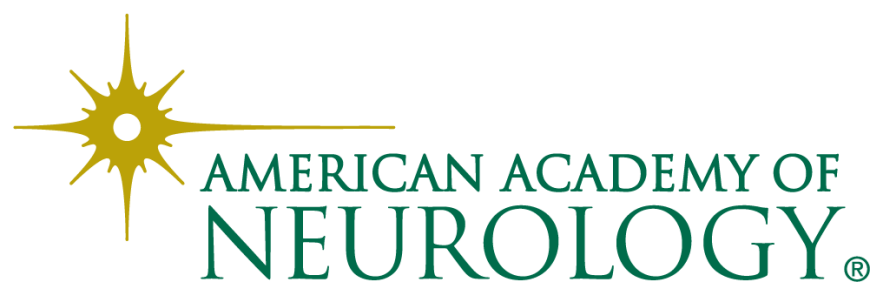

